\title{
Posterior reversible encephalopathy syndrome after nontransplant cardiac surgery
}

\author{
John R. Mehall, MD, ${ }^{a}$ James L. Leach, $M D{ }^{b}$ and Walter H. Merrill, MD, ${ }^{a}$ Cincinnati, Ohio
}

$\mathrm{W}$ e present the case of a patient in whom a reversible neurocognitive deficit developed after aortic valve replacement surgery. The posterior reversible encephalopathy syndrome (PRES) has been described in relation to a variety of medical and postoperative conditions, but it has not been previously reported as a complication of nontransplant cardiac surgery. Major features, diagnosis, and management of PRES are described.

\section{Clinical Summary}

A 78-year-old woman with severe aortic stenosis underwent aortic valve replacement. Her operation was uneventful; postoperatively, the patient had systolic hypertension up to $180 \mathrm{~mm} \mathrm{Hg}$ requiring sodium nitroprusside for adequate control. The patient was extubated and neurologically intact the evening of the operation. On the morning of postoperative day 1 , acute onset of altered mental status, left upper extremity weakness, right-deviated gaze, and facial droop developed. She was taken immediately for computed tomography of the head, which documented no abnormalities. Six hours after the neurologic change, the patient had a tonic-clonic seizure. For the next 24 hours the patient remained obtunded, responding only to painful stimuli, with right-deviated gaze. During this time mean blood pressure was maintained above $140 \mathrm{~mm}$ Hg. Repeat computed tomography of the head 48 hours after the event documented no abnormalities, and the patient was referred for magnetic resonance imaging (MRI). MRI of the brain demonstrated edema primarily involving the white matter of the posterior cerebral hemispheres (Figure 1). These findings are typical of vasogenic edema and nearly pathognomonic for the PRES. The patient's blood pressure was lowered and tightly controlled at less than $120 \mathrm{~mm} \mathrm{Hg}$ systolic, and she experienced progressive improvement. By 10 days postoperatively the patient was awake with appropriate mentation and no residual deficits.

\section{Discussion}

PRES is a clinical syndrome of altered mental status, hypertension, and posterior white matter edema that, with appropriate blood

\footnotetext{
From the Department of Surgery, Section of Cardiothoracic Surgery, ${ }^{\mathrm{a}}$ and the Department of Radiology, ${ }^{b}$ University of Cincinnati, Cincinnati, Ohio.

Received for publication June 28, 2005; accepted for publication July 19, 2005 .

Address for reprints: John R. Mehall, MD, University of Cincinnati, 231 Albert B. Sabin Way, PO Box 670558, Cincinnati, OH 45267-0558 (E-mail: john.mehall@uc.edu).

J Thorac Cardiovasc Surg 2005;130:1473-4

$0022-5223 / \$ 30.00$

Copyright $\odot 2005$ by The American Association for Thoracic Surgery

doi:10.1016/j.jtcvs.2005.07.030
}

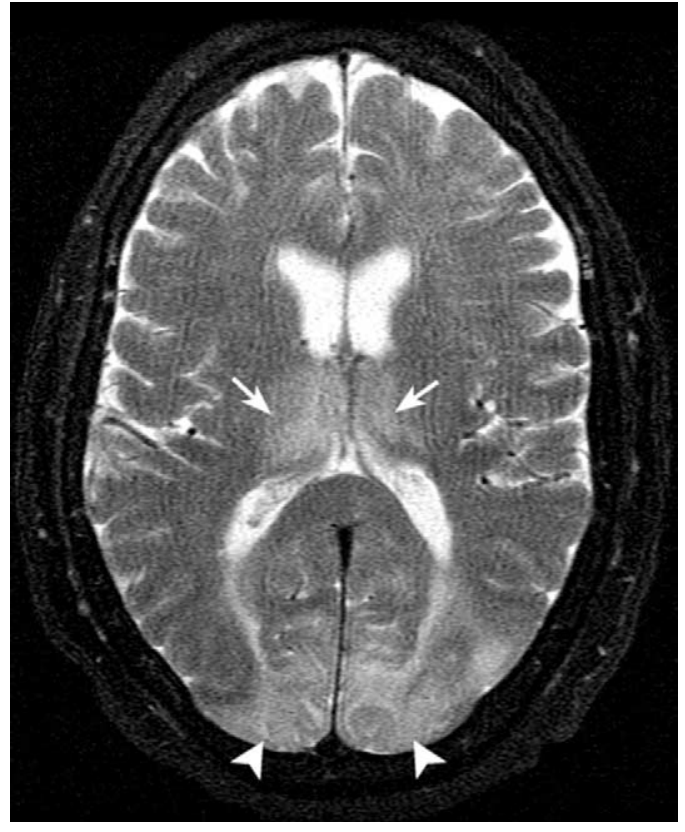

Figure 1. Axial fast spin echo T2-weighted image (repetition time [TR]: 4000; echo time [TE]: 78.7; echo train [ET]: 12) on postoperative day 3. MRI reveals areas of T2 hyperintensity involving both thalami (arrows) and both occipital lobes (arrowheads). The occipital signal abnormality involves both cortex and subjacent white matter. The occipital sulci are effaced.

pressure control, can be completely reversible. The largest published series includes 15 patients in whom the most common symptoms were seizures (11/15), visual abnormalities (10/15), headache with nausea and vomiting (8/15), lethargy (6/15), and confusion (4/15). ${ }^{1}$ In this report most patients had more than one of these symptoms, and hypertension was present in 14 of 15 . The onset of symptoms is usually subacute but may be sudden, with seizures being more common early in the course of the illness. The diagnosis of PRES is usually established by MRI. Typical MRI features include occipital and parietal lobe white matter that is isointense or hypointense on T1 images, and hyperintense on $\mathrm{T} 2$-weighted images. With control of hypertension, the clinical and imaging findings usually resolve completely within 14 days of onset. ${ }^{2}$ In the absence of appropriate blood pressure control, symptoms can become permanent.

PRES has been associated with a wide range of diagnoses, but it is most often linked with severe hypertension (malignant hypertension, eclampsia and HELLP syndrome [hemolysis, elevated liver enzymes, and low platelet count], and renal related hypertension) and 
immunosuppression. Multiple reports of PRES in transplant patients receiving cyclosporine, tacrolimus, or both, exist in the literature. Similarly, PRES has been noted to develop in patients receiving rituximab infusion, chemotherapy, and bone marrow transplantation. PRES has also been seen in 5 patients after carotid endarterectomy, ${ }^{4}$ all of whom had significant postoperative hypertension. Two posttransplant patients on immunosuppression (one kidney, one heart) are also reported to have had PRES postoperatively. ${ }^{5}$

The timely differentiation between PRES and ischemic cerebral insults is important because the treatment paradigms are opposite. Although cardiac surgery patients are more prone to have neurologic changes caused by ischemia, the potential reversibility and differing treatment plan for PRES make timely recognition of this entity important.

\section{References}

1. Hinchey J, Chaves C, Appignani B, Breen J, Pao L, Wang A, et al. A reversible posterior leukoencephalopathy syndrome. $N$ Engl J Med. 1996;334:494-500.

2. Garg RK. Posterior leukoencephalopathy syndrome. Postgrad Med J. 2001;77:24-8

3. Bartynski WS, Zeigler Z, Spearman MP, et al. Etiology of cortical and white matter lesions in cyclosporine-A and FK-506 neurotoxicity. Am J Neuroradiol. 2001;22:1901-14.

4. Karapanayiotides T, Meuli R, Devuyst G, Piechowski-Jozwiak B, Dewarrat A, Ruchat P, et al. Postcarotid endarterectomy hyperperfusion or reperfusion syndrome. Stroke. 2005;36:21-8.

5. Lanzino G, Cloft H, Hemstreet MK, West K, Alston S, Ishitani M. Reversible posterior leukoencephalopathy following organ transplantation: description of two cases. Clin Neurol Neurosurg. 1997; 99:222-6. 